\title{
The Danish Adult Diabetes Registry
}

This article was published in the following Dove Press journal:

Clinical Epidemiology

25 October 2016

Number of times this article has been viewed

\section{Marit Eika Jørgensen ${ }^{1,2}$ \\ Jette K Kristensen ${ }^{3}$ \\ Gitte Reventlov Husted' \\ Charlotte Cerqueira ${ }^{4}$ \\ Peter Rossing ${ }^{1,3,5}$}

'Steno Diabetes Center, Gentofte, ${ }^{2}$ National Institute of Public Health, University of Southern Denmark,

Odense, ${ }^{3}$ Aarhus University, Aarhus,

${ }^{4}$ Registry Support Centre (East) -

Epidemiology and Biostatistics,

Research Centre for Prevention and Health, Capital Region of

Denmark, ${ }^{5}$ University of Copenhagen,

Copenhagen, Denmark
Correspondence: Peter Rossing Steno Diabetes Center, Niels Steensens Vej 2, DK 2820 Gentofte, Denmark

Tel +453075 7310

Email pro@steno.dk
Aim of the database: The aim of the Danish Adult Diabetes Registry (DADR) is to provide data from both the primary health care sector (general practice [GP]) and the secondary sector (specialized outpatient clinics) to assess the quality of treatment given to patients with diabetes. The indicators represent process and outcome indicators selected from the literature.

Study population: The total diabetes population in Denmark is estimated to be $\sim 300,000$ adult diabetes patients. Approximately $10 \%$ have type 1 diabetes, which is managed mainly in the secondary sector, and $90 \%$ have type 2 diabetes with the majority $(80 \%)$ being treated in primary health care. In 2014, DADR included data from a total of 70,826 patients.

Main variables: The following variables are assessed: date of analysis as well as the outcome for hemoglobin A1c, blood pressure, lipids, urinary albumin-creatinine ratio, smoking status, glucose-, blood pressure-, and lipid-lowering treatment (yes/no), insulin pump treatment (yes/ no), and date of last eye and foot examination.

Descriptive data: In 2014, the annual report included data regarding over 38,000 patients from outpatient clinics, which is assumed to have included almost all patients in this setting, and $>32,000$ from GPs, reflecting improved but still limited coverage from this setting. The annual results are published in a compiled report of Danish Diabetes Care, which included DADR, data from the pediatric diabetes database, and the national ophthalmological diabetes database. The annual report is published, which included data on national, regional, and local level (individual outpatient clinics and corresponding GPs). This allows a comprehensive overview of diabetes care in Denmark.

Conclusion: The database covers an increasing fraction of patients with diabetes in Denmark, and the structure for full coverage is in place. Annual reporting has helped to ensure focus on the quality of diabetes treatment in the primary and secondary health care. Furthermore, it is an important resource for Danish register-based diabetes research.

Keywords: diabetes, national registry, epidemiology, quality of care

\section{Background}

Diabetes is a widespread chronic disease with $>300,000$ patients in Denmark. Approximately $10 \%$ have type 1 diabetes, which is managed primarily in outpatient clinics, and 90\% have type 2 diabetes, among whom the majority $(80 \%)$ are treated in primary health care.

The treatment has evolved in recent decades, with better options for education, self-care, and individualized insulin treatment with pens and pumps, focus on multifactorial intervention including lifestyle modification, and control of glucose, blood pressure, and lipids. As a result, the prognosis for patients has improved considerably 
regarding the development of micro- and macrovascular complications and survival. ${ }^{1-5}$ Structured care with regular screening for complications and targeted intervention has been important for this development.

\section{Aim}

Quality monitoring is necessary to ensure that patients with type 1 and type 2 diabetes in Denmark benefit from current improvements in care, and are treated according to nationally agreed treatment guidelines. The aim of the Danish Adult Diabetes Registry (DADR) (initially The National Indicator Project for Diabetes) is to provide data from both the primary health care sector (general practice [GP]) and the secondary sector (specialized outpatient clinics) to assess the quality of treatment given to patients with diabetes, with respect to selected well-documented and treatment-relevant process and result indicators. The registry has published an annual report since 2005 .

\section{Study population}

All diabetes outpatient clinics have had an obligation to report to the database since 2004, data from the GPs were included from 2006, and inclusion became mandatory from 2014. The reporting is done through various information technology systems ranging from manual data entry from paper records to automated data capture from electronic patient records.

As $>80 \%$ of patients with type 2 diabetes are taken care of by GPs, the reporting from primary care to the DADR has been a very important and unique feature, compared to most other registries relying on secondary health care data.

\section{Main variables and quality indicators}

National evidence-based guidelines for treatment and control have been developed to guide clinicians toward optimal treatment for all patients. ${ }^{6,7}$ Furthermore, disease management programs, defined as the total cross-disciplinary, multisectoral, and coordinated health care services for a given chronic condition, have been evolved to create a framework that ensures the application of evidence-based recommendations for health care intervention, including a precise description of tasks and coordination between all parties involved.

To ensure the indicators are perceived as relevant and meaningful for reporting GPs and hospital units, indicators have been selected for quality assessment, covering aspects of cardiometabolic control and complication-screening activity. To reduce burden of reporting results, the number of variables initially had to be limited. Selection of indicators has been based on the following criteria: 1) a strong association with disease progression and prognosis, 2) standardized measurability, and 3) comparability across reporting units. Consequently, indicators of, for example, lifestyle, such as diet and physical activity, have so far been opted out, due to lack of a standardized tool for monitoring in clinical practice. Besides basic information on age, sex, and year of diabetes diagnosis, the following variables are reported annually to the DADR: glycated hemoglobin A1c (HbA1c), blood pressure, lipids, urinary albumin-creatinine ratio, estimated glomerular filtration rate, body mass index, smoking status, glucose-, blood pressure-, and lipid-lowering treatment (yes/ no), insulin pump treatment (yes/no), date of last eye examination result known by the treating physician, and date of last foot examination. For each indicator, the steering committee for the database has agreed on a standard that the program should aim to reach. Figures 1 and 2 present the development in completeness over time for selected variables.

Derived process indicators and standards include:

- Annual measurement of HbA1c with a standardized method in $95 \%$ of patients

- Annual measurement of blood pressure in $95 \%$ of patients

- Measurement of lipids every second year in $90 \%$ of patients

- Foot examination in $95 \%$ of patients within 2 years

- Examination of urinary albumin-creatinine ratio in $95 \%$ of patients within 2 years

- Eye examination within a 2 -year period in $90 \%$ of patients and within a 4 -year period in $95 \%$ of patients

- Prescribed antidiabetic treatment among patients with HbA1c $\geq 53 \mathrm{mmol} / \mathrm{mol}$ (no standard decided upon yet)

- Prescribed antihyptertensive treatment among patients with blood pressure $\geq 140 / 90 \mathrm{mmHg}$ (standard 80\%)

- Prescribed lipid-lowering medication among patients with low-density lipoprotein cholesterol $>2.5 \mathrm{mmol} / \mathrm{L}$ (no standard decided upon yet)

- Prescribed renin-angiotensin system blockade among patients with micro- or macroalbuminuria (no standard decided upon yet)

In the annual report, the indicators are presented separately for primary and secondary health care on a national, regional, and local level (with primary care data shown for clusters referring to the same outpatient clinic). In addition, each outpatient clinic or GP has access to their own quality data. This allows a comprehensive overview of diabetes care in Denmark. Table 1 presents an example of the data. 


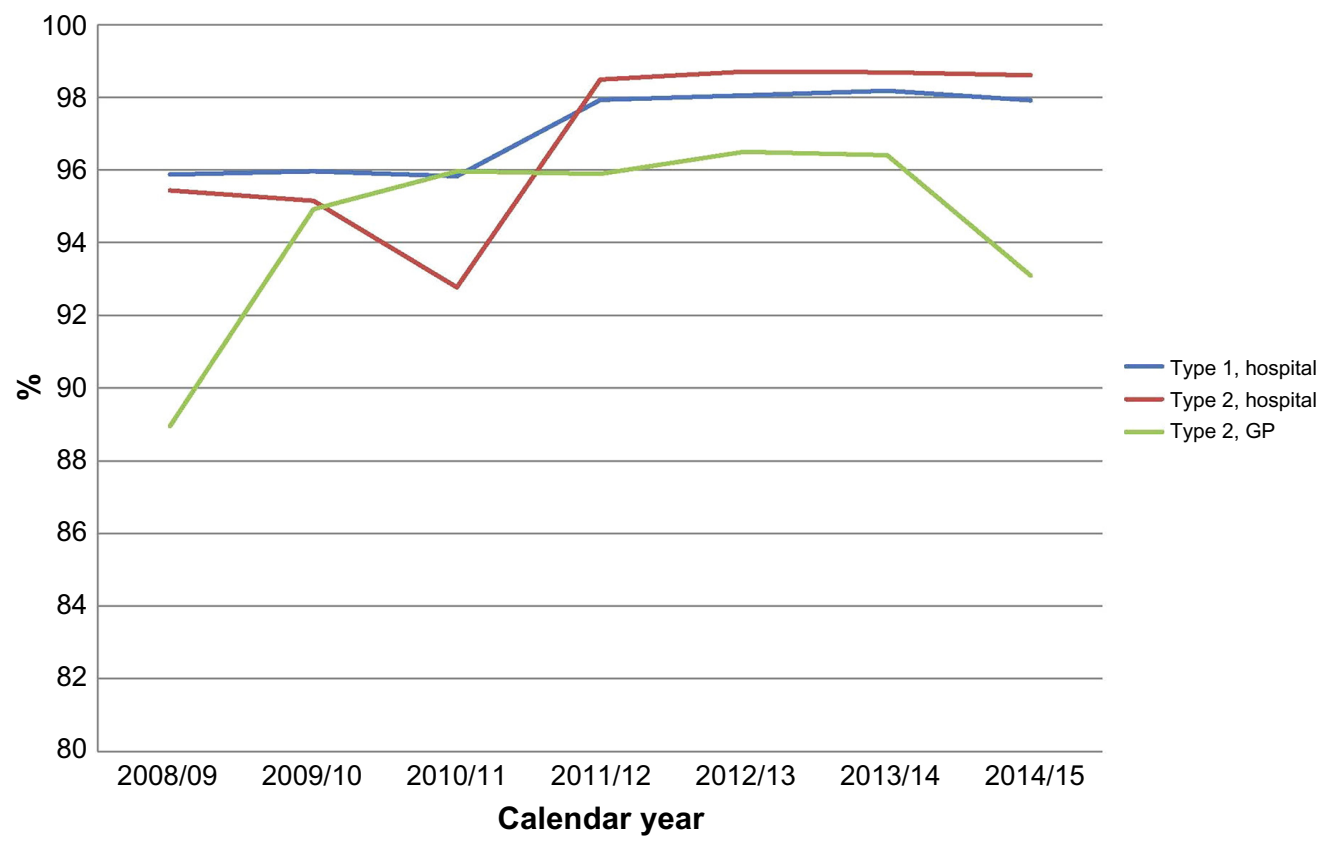

Figure I Change in completeness for reporting of $\mathrm{HbAlc}$ values over time.

Notes: The figure shows that change was measured and reported for the majority of patients. Technical problems with reporting were expected to be responsible for the 2010/II drop.

Abbreviations: HbAlc, hemoglobin Alc; GP, general practice.

\section{Follow-up}

It is an ongoing focus to ensure valid data. Validity is evaluated and discussed on regional and national audits, and when compared to other registries of patients in outpatient clinics in Denmark, it is estimated that the data coverage is
$97 \%$ in 2014. Figure 1, 2, and 3 presents the development over time. Particularly in the beginning of the project, it has been a challenge. Currently, it is estimated that data completeness from the outpatient clinics, matching data to the administrative data in the Danish National Patient Register

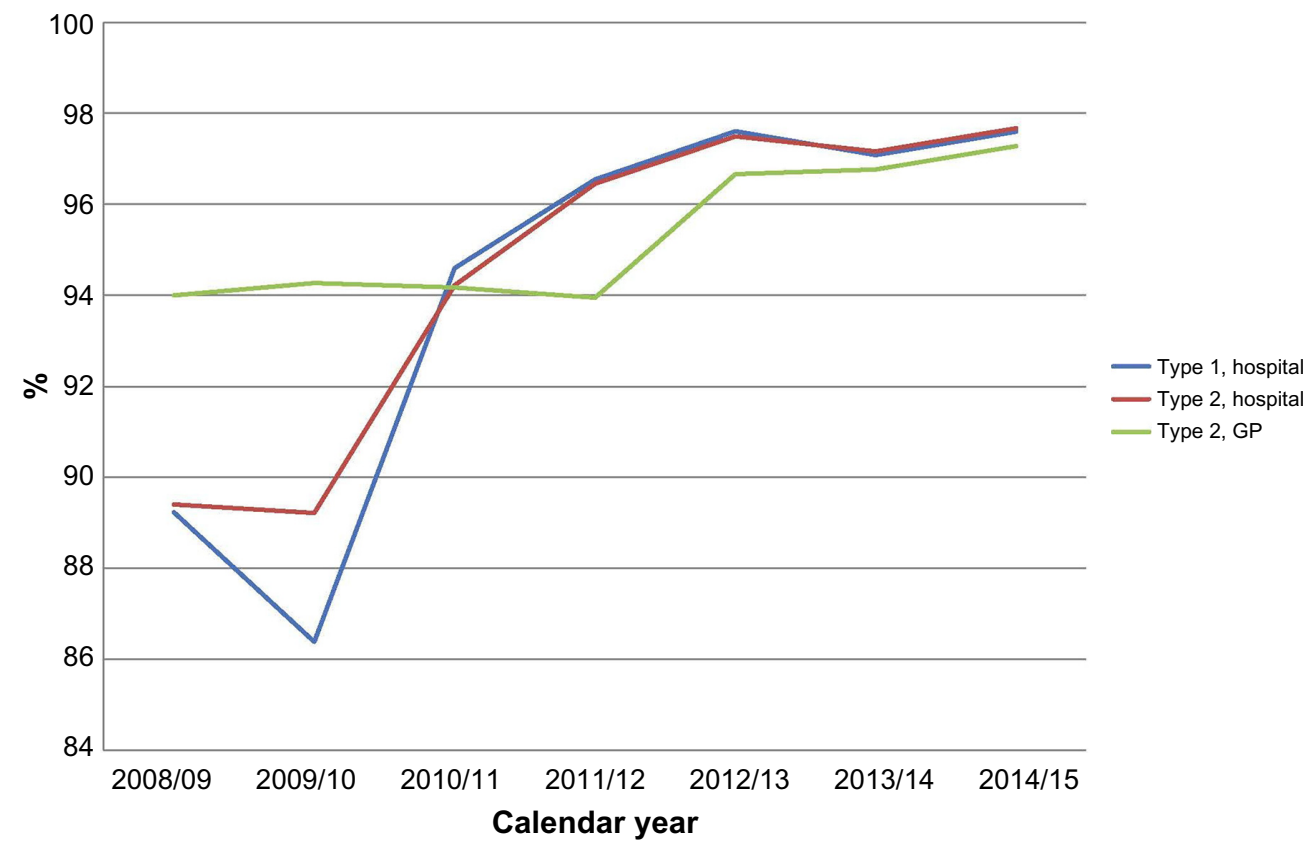

Figure $\mathbf{2}$ Change in completeness for reporting of smoking habits over time.

Notes: The figure shows that change was measured and reported for an increasing number of patients in outpatient clinics, and is now high in both primary and secondary health care settings.

Abbreviation: GP, general practice. 
Table I Foot examination within a 2-year period

\begin{tabular}{|c|c|c|c|c|c|c|c|}
\hline \multicolumn{8}{|c|}{ Proportion of diabetes patients receiving a foot examination within a 2-year period } \\
\hline \multirow[t]{3}{*}{ Region } & \multirow[t]{3}{*}{ Std met? } & \multirow{3}{*}{$\begin{array}{l}\text { Nominatorl } \\
\text { denominator }\end{array}$} & \multirow{3}{*}{$\begin{array}{l}\text { Unknown } \\
\text { (\%) }\end{array}$} & \multirow{2}{*}{\multicolumn{2}{|c|}{$\begin{array}{l}\text { Current year } \\
\text { March I, 20I4-February } \\
28,2015\end{array}$}} & \multicolumn{2}{|c|}{ Earlier years } \\
\hline & & & & & & \multirow{2}{*}{$\begin{array}{l}2013 / 14 \\
\text { Prop }\end{array}$} & \multirow{2}{*}{$\begin{array}{l}2012 / 13 \\
\text { Prop } \\
\end{array}$} \\
\hline & & & & Prop & $95 \% \mathrm{Cl}$ & & \\
\hline $\begin{array}{l}\text { Hospital units, } \\
\text { total }\end{array}$ & Yes & $36,504 / 38,350$ & $0(0)$ & 95 & $95-95$ & 96 & 96 \\
\hline $\begin{array}{l}\text { Capital Region of } \\
\text { Denmark }\end{array}$ & Yes & $13,549 / 14,300$ & $0(0)$ & 95 & $94-95$ & 94 & 95 \\
\hline Region Zealand & Yes & $4,221 / 4,359$ & $0(0)$ & 97 & $96-97$ & 97 & 93 \\
\hline $\begin{array}{l}\text { Region of } \\
\text { Southern Denmark }\end{array}$ & Yes & $10,119 / 10,334$ & $0(0)$ & 98 & $98-98$ & 98 & 98 \\
\hline $\begin{array}{l}\text { Central Denmark } \\
\text { Region }\end{array}$ & Yes & $5,833 / 6,|5|$ & $0(0)$ & 95 & $94-95$ & 96 & 96 \\
\hline $\begin{array}{l}\text { North Denmark } \\
\text { Region }\end{array}$ & No & $2,782 / 3,206$ & $0(0)$ & 87 & $86-88$ & 92 & 92 \\
\hline $\begin{array}{l}\text { General practices, } \\
\text { total }\end{array}$ & No & $24,823 / 32,128$ & $0(0)$ & 77 & 77-78 & 81 & 85 \\
\hline Capital Region of Denmark & No & $7,082 / 9,210$ & $0(0)$ & 77 & $76-78$ & 81 & 86 \\
\hline Region Zealand & No & $4,160 / 5,436$ & $0(0)$ & 77 & $75-78$ & 79 & 83 \\
\hline $\begin{array}{l}\text { Region of } \\
\text { Southern Denmark }\end{array}$ & No & $5,248 / 6,697$ & $0(0)$ & 78 & 77-79 & 84 & 88 \\
\hline $\begin{array}{l}\text { Central Denmark } \\
\text { Region }\end{array}$ & No & $5,991 / 7,769$ & $0(0)$ & 77 & $76-78$ & 80 & 83 \\
\hline $\begin{array}{l}\text { North Denmark } \\
\text { Region }\end{array}$ & No & $2,342 / 3,016$ & $0(0)$ & 78 & $76-79$ & 82 & 88 \\
\hline
\end{tabular}

Abbreviations: Std, standard; Prop, proportion; Cl, confidence interval.

on all hospital contacts, is up to $95 \%$. Furthermore, the setup has proved to be able to capture data from all outpatient clinics, and all GPs. Approximately $10 \%$ of the data are entered manually into a data system, whereas the remaining $90 \%$ are captured directly from the electronic medical record systems, which minimize risk of data entry errors.

Unfortunately, uncertainty regarding data security and database approvals has stopped delivery of data from the GPs since September 2014, affecting primarily completeness of data regarding type 2 diabetes.

The annual 2014 report included data regarding over 38,000 patients from outpatient clinics, which is assumed to have included almost all patients in this setting, and $>32,000$ from GPs (collected before September 2014). The annual results are published in a compiled report of Danish Diabetes Care, which included DADR, data from the pediatric diabetes database, and the national ophthalmological diabetes database. ${ }^{1}$

The reported results are discussed at annual meetings. At the national audit, the indicators and standards for good clinical practice and care for patients with diabetes are discussed, and recommendations are agreed upon. In case of outlier results, local audit is recommended. The final report, including recommendations for improvement, is published online at https://www.sundhed.dk. ${ }^{8}$

\section{Use of the database for research}

The nationwide reporting of unbiased, valid, and standardized information to the registry makes it attractive for research purposes. The unique Danish personal identification number allows linkage at the individual level of the database with other Danish registers, for example, the National Patient Register and the cause of death register, offering opportunities to study differences in treatment and control across geographical and other specified subpopulations. For example, the DADR has been used for follow-up of the Danish Centre for Strategic Research in Type 2 Diabetes (DD2) cohort for information about prescription of antidiabetic therapies in newly diagnosed diabetes. ${ }^{9}$ Another epidemiological study has linked information from the DADR with information from the Danish Civil Registration System on country of origin. In a research field where longitudinal data were lacking, this study demonstrated a higher incidence of most micro- and macrovascular complications among migrants with diabetes from Sub-Saharan Africa, Middle East, and Asia compared to Danish born. These ethnic differences 


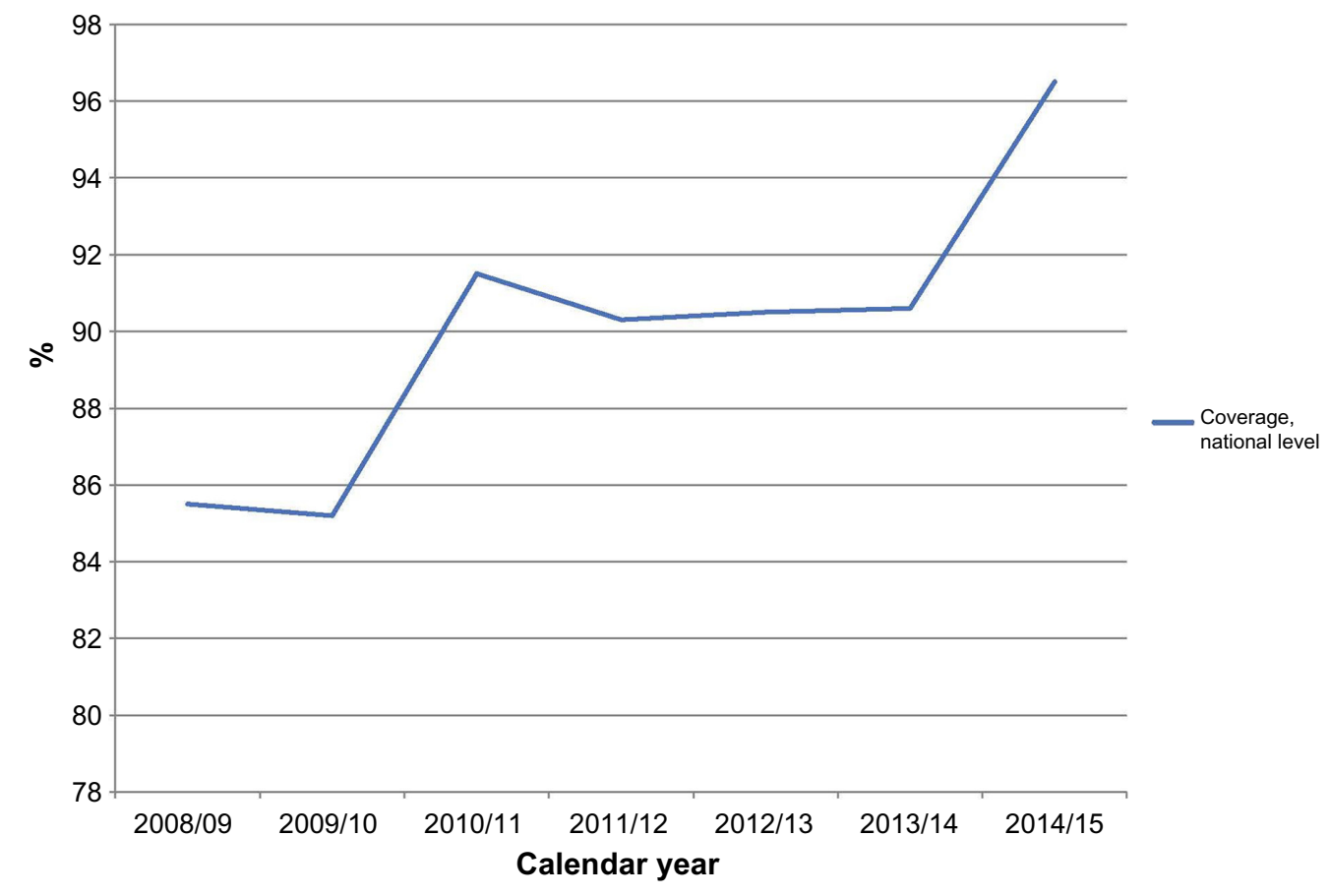

Figure 3 Coverage of the diabetes register over time for patients in outpatient clinics in secondary care.

Notes: The coverage was assessed by comparing number of individual patients reported to the register, with data from administrative hospital systems on patient visits in the clinics.

persisted after adjustment for a wide range of confounders, including HbA1c, blood pressure, lipids, body mass index, smoking, diabetes duration, age, and sex. ${ }^{10}$

The number of published studies based on the registry is still limited, probably reflecting initial concerns about data validity and coverage. As these concerns have been resolved, there has been a steady increase in applications for data, and as the coverage of the patient population and duration of follow-up increases, the database will provide a valuable data source for Danish register-based diabetes research.

\section{Administrative issues and funding}

During the past decade, reporting has been increasingly automated and valid. However as mentioned, a recent discussion on data protection agreements has stopped data delivery from GPs. As the majority of patients are seen by GPs, an overview of diabetes care in Denmark will be far from complete without these data, so it is crucial that data will soon again be reported.

The registry is funded by the Danish Regions and administered by the Danish Clinical Registries (Regionernes Kliniske Kvalitetsudviklings Program) that constitute the infrastructure of the national clinical quality databases in Denmark.

The registry is run by a steering committee with representatives both from the secondary and the primary sector from the five regions, and from the Danish Diabetes Association.

\section{Conclusion}

The database has helped significantly to ensure the quality of diabetes treatment in the primary and secondary health care sector in Denmark and can continue to do so if data from the GPs are included again. Furthermore, it is an important resource for Danish register-based diabetes research.

\section{Acknowledgment}

This paper was funded by the Program for Clinical Research Infrastructure established by the Lundbeck Foundation and the Novo Nordisk Foundation and administered by the Danish Regions.

\section{Disclosure}

The authors report no conflicts of interest in this work.

\section{References}

1. Gaede P, Lund-Andersen H, Parving HH, Pedersen O. Effect of a multifactorial intervention on mortality in type 2 diabetes. $N$ Engl J Med. 2008;358(6):580-591.

2. Andresdottir G, Jensen ML, Carstensen B, et al. Improved survival and renal prognosis of patients with type 2 diabetes and nephropathy with improved control of risk factors. Diabetes Care. 2014;37(6): 1660-1667.

3. Faerch K, Carstensen B, Almdal TP, Jorgensen ME. Improved survival among patients with complicated type 2 diabetes in Denmark: a prospective study (2002-2010). J Clin Endocrinol Metab. 2014;99(4): E642-E646.

4. Jorgensen ME, Almdal TP, Carstensen B. Time trends in mortality rates in type 1 diabetes from 2002 to 2011. Diabetologia. 2013;56(11):2401-2404. 
5. Jorgensen ME, Almdal TP, Faerch K. Reduced incidence of lower-extremity amputations in a Danish diabetes population from 2000 to 2011. Diabet Med. 2014;31(4):443-447.

6. Dansk Selskab for Almen Medicin: Type 2 diabetes - et metabolisk syndrom, Denmark, 2012. Available from: http://vejledninger.dsam.dk/ type2/. Accessed March 7, 2016. Danish.

7. Dansk Endokrinologisk Selskab: Type 1 diabetes mellitus, Copenhagen, 2014. Available from: http://endocrinology.dk/index.php/ nbvhovedmenu/1-diabetes-mellitus/3-type-1-diabetes-mellitus. Accessed March 7, 2016. Danish.

8.Danish Diabetes Database, national annual report 2014-15. Available from: https://www.sundhed.dk/content/cms/87/4687_ kom_\%C3\%A5rsrapport_diabetes_2014_15_27082015_endelig.pdf. Accessed March 7, 2016.
9. Andersen GS, Jørgensen ME, Søberg S. Ethnicity, migration and T2DM [Internet]. Diapedia. 2015. Available from: http://dx.doi.org/10.14496/ dia.3104465162.16. Accessed March 7, 2016.

10. Mor A, Berencsi K, Svensson E, et al. Prescribing practices and clinical predictors of glucose-lowering therapy within the first year in people with newly diagnosed Type 2 diabetes. Diabet Med. 2015;32(12):1546-1554.

\section{Publish your work in this journal}

Clinical Epidemiology is an international, peer-reviewed, open access, online journal focusing on disease and drug epidemiology, identification of risk factors and screening procedures to develop optimal preventative initiatives and programs. Specific topics include: diagnosis, prognosis, treatment, screening, prevention, risk factor modification,

Submit your manuscript here: http://www.dovepress.com/clinical-epidemiology-journal

\section{Dovepress}

systematic reviews, risk \& safety of medical interventions, epidemiology \& biostatistical methods, and evaluation of guidelines, translational medicine, health policies \& economic evaluations. The manuscript management system is completely online and includes a very quick and fair peer-review system, which is all easy to use. 